\title{
OPUS DEI
}

\author{
Raimon Bonal \\ UNIVERSITAT DE BARCELONA. FUNDACIO JAUME BOFILL
}

\section{Historia}

El 9 de gener del 1902 neix a Barbastre (Osca) José M. Escrivá de Balaguer i Albàs, el segon d'una família que tindrà sis fills. El pare, juntament amb dos socis, té un negoci de xocolata ide teixits i la mare, d'una generació de tretze germans, té antecedents francesos. A casa es respira un ambient de sòlida pietat $i$ esdevé una llar plena de virtuts humanes. No ho té facil, la família Escrivá: tres de les quatre filles es moren en tres anys, el negoci no prospera $i$ han de crear un nou negaci a Logronyo.

José Maráa comença els estudis a l'escola del poble, i als 17 anys abandona el seu projecte d'ésser arquitecte i decideix entrar al seminari. El 1918 inicia els seus estudis eclesiàstics al seminari de Logronyo i el 1920 els continua al de Saragossa: el 1922 serà superior del seminari per ordre del cardenal Soldevila. Abans d'acabar la Teologia, comença a estudiar Dret i al març del 1925 és ordenat sacerdot quan feia pocs mesos que havia mort el seu pare.

Després d'una breu estada en una substitució a una parròquia rural, s'instal.la a Saragossa per seguir els seus estudis de dret i dóna classes de Dret Romà i de Dret Canònic en una acadèmia privada amb la intenció d'ajudar els de casa (la mare, una germana i el germà petit), que han quedat al seu càrrec. Al març del 1927 se'n va a Madrid a fer el doctorat en Dret Canònic.

El 2 d'octubre del 1928, mentre està realitzant uns exercicis espirituals, "veu" (en expressió seva) el que Déu espera d'ell: ha d'aconseguir que els homes de totes les classes socials, començant pels intel-lectuals, responguin a una vocació específica consistent a buscar la santedat i fer apostolat enmig del món, en l'exercici de la seva professió i sense canviar d'estat. Per traduir el seu projecte, somés disposava dels seus 26 anys, la gràcia de Déu i un bon humor, segons diuen els seus biògrafs.

Malgrat haver explicitat que a l'Opus Dei no hi hauria dones "ni de broma", el 14 de febrer del 1930 una altra inspiració divina l'hi fa veure que el missatge de santificació enmig del món també pot ésser viscut per les dones; és per això que l'Opus Dei consta de dues seccions completament separades, encara que amb un idèntic esperit.

No totes les vocacions inicials prosperen i ja a final del 1933 s'obre l'acadèmia DYA (Dret i Arquitectura), que serà la primera obra corporativa de l'Opus Dei. Després, es crearà una residència universitària que la Guerra Civil destruirà.

La Guerra Civil espanyola el va obligar a passar la frontera al desembre del 1937. La fugida va durar catorze dies, perquè via Lourdes i Andorra torna a entrar a Espanya i fa un assentament fix a Burgos. Després de la guerra, tornarà a Madrid, on al cap de cinc mesos obre una nova residència, essent encara ell l'únic sacerdot de l'Opus Dei (nom donat per un amic en formular a Escrivá la pregunta: "com va aquesta obra de Déu?"); inicia aleshores una forta activitat apostòlica els caps de setmana per moltes i diverses ciutats espanyoles dirigint persones, fent exercicis espirituals, conferències i contactes. 
El 1941 Leopoldo Eijo Garay, bisbe de Madrid-Alcalà, reconeix a la seva diocesi l'Opus Dei com a "Pia Unió", la primera promoció legal de l'Obra. A partir d'aquest moment, la progressió jurídica dintre l'Església esdevé ja imparable: el 1943, Institut Comunitari sense Vots Públics; el 1950, Institut Secular de Dret Pontifici; el 1982, Prelatura sense Territori.

Des del 1943 José María Escrivá pensava en la possibilitat d'ordenar membres laics de l'Obra que, amb un idèntic esperit, assegurarien la formació, facilitarien la projecció apostolicai serien la garantia de la puresa d'esperit i de la unitat de l'Obra. El 25 de juny del 1944 el bisbe de Madrid-Acalà ordena els tres primers sacerdots i és així com va néixer la Societat Sacerdotal de la Santa Creu, inseparable de l'Opus Dei i que representà en l'Església un nou fenomen pastoral: sacerdots amb títol acadèmic superior de caràcter civil, que han exercit la seva professió i que "serviran sense retribució totes les ànimes i especialment les dels seus germans".

L'Opus Dei el constitueixen tots, sacerdots i seglars, encara que la Societat Sacerdotal de la Santa Creu és el nucli central dels sacerdots que porten l'Obra. Aquests, a Catalunya, són una seixantena que han estat escollits per ésser ordenats dintre de l'Obra per la seva especial vocació. No s'ha de confondre amb els capellans diocesans que són socis de l'Obra, als quals l'Opus Dei dóna l'oportunitat d'una formació religiosa i d'un sosteniment espiritual; aquests deuen obedièncin al bisbe diocesà, al contrari dels primers, que la deuen al prelat de l'Opus Dei.

A la fi del 1946. El Fundador s'instal-la a Roma amb la finalitat d'estar en el cor de la cristiandat, prop del vicari de Crist, i posar de manifest la dimensió universal de l'Opus Dei; d 1948 s'hi erigeix el Col-legi Romà de la Santa Creu per als homes (és on es troba el centre de govern de l'Opus Dei: Bruno Buozzi, 75) i el 1953, el Col·legi Romà de Santa Maria per a les dones. El 1947, Monsenyor Escrivá serà prelat domèstic de Sa Santedat, càrrec honorífic que li donava dret a dir-se monsenyor, i el 1968 serà també nomenat marquès de Peralta.

La seva estada a Roma es veu interrompuda constantment pels viatges arreu del món fent reunions o tertúlies amb grups diversos de persones. I el fundador va governar l'Obra assistit d'un Consell per a cada secció (homes i dones) fins a la seva mort, ocorreguda el 26 juny del 1975. E 15 de setembre del mateix any s'elegia el successor, Alvaro del Portillo, un dels seus primers companys en l'aventura i que havia estat durant quaranta anys el seu més íntim col-laborador.

Esdevinguda prelatura personal, el bisbe n'és Alvaro del Portillo i el seu vicari general, Javier Echevarría, preparat al sacerdoci per Escrivá i del Portillo i ordenat el 7 d'agost del 1955. L'Opus és una estructura controlada pels espanyols i la seva internacionalitat proclamada es veurh quan calgui succeir l'actual "Padre", puix que els candidats són dos: el mateix Echevarría, que aviat compleix el seu mandat, i Flavio Capucci, italià, postulador en el procés de canonització d'Escrivá (causa oberta el 12 de maig del 1981) ${ }^{1}$.

L'expansió de l'Opus Dei a nivell internacional es realitza bàsicament amb posterioritat a la Segona Guerra Mundial: Portugal (1945), Anglaterra i Itàlia (1946), França i Irlanda (1947), Estats Units i Mèxic (1949), Xile i Argentina (1950), Colòmbia i Veneçuela (1951), Alemanya (1952), Perú i Guatemala (1953), Uruguai i Suīssa (1956), Brasil, Austria i Canadà (1957), E Salvador, Kenya i Japó (1958), Costa Rica (1959), Holanda (1960), Paraguai (1962), Australlia (1963), Filipines (1964), Nigèria i Bèlgica (1965), Puerto Rico (1969), etc. Segons les dades més

1 Un numerari ens deia: "L'Opus no va poder tenir capellans incardinats a l'Obra fins que va ésser una Pia Unio reconeguda pel bisbe de Madrid el 1941 i per Roma amb els primeres ordenacions sacerdotals el 1943. El 1950 serà un institut secular i el 1984 una prelatura personal. Aquesta no és una excepcionalitat, puix que també es dóna a l'exèrcit, $\infty$ hi ha el Vicari General Castrense, que és el bisbe dels militars i al qual deuen obediència i és el responsable de la seva vida espiritual. Hi ha bisbes especificament ordenats, no per atendre una diðcesi territorial, sinó per atendre unes determinader persones".

Un sacerdot diocesà de l'Opus: "Hem de considerar dues dimensions: la teologica i la canònica. Des de la primera, a l'Opus Dei tots participem del mateix esperit i vivim les mateixes realitats sobrenaturals; des de la perspectiva canonica, la prelatura personal té el seu presbiteri $i$, per tant, uns sacerdots vinculats per obedièscia amb el prelat". 
recents, l'Opus Dei està penetrant fortament als països de l'Est, on, donada la seva nova orientació respecte a la llibertat religiosa i amb la manca de càrrecs directius que pateixen, hi ha un ampli camp d'apostolat a realitzar.

Les vocacions són incomptables i, segons dades publicades pel mateix Opus Dei, el 1984, nou anys després de la mort del seu fundador, l'Opus Dei tenia 74.000 membres en 87 països diferents. Des del 1975, es treballa a Bolívia, Hondures, Trinidad i Tobago, Costa d'Ivori, Zaire, Hong-Kong i Singapur; des de 1983, als països escandinaus².

Des de la dècada dels anys 70 , i donada l'amistat i la sintonia ideològica de Monsenyor Escrivá de Balaguer i l'actual papa, des que era encara cardenal de Cracovia, l'Opus Dei va obtenir resultats excel-lents a Polònia en la dècada passada utilitzant dos instruments: les Residències Universitàries Internacionals i l'Institut per a la Cooperació Universitària. L'expansió internacional de l'Opus Dei no ha dit encara la seva darrera paraula.

Però l'Opus Dei és una fundació espanyola, no solament per l'origen del seu fundador, sinó per la seva irradiació centrifuga a partir d'Espanya. L'Obra ha anat substituint progressivament els jesuites en l'educació de les classes acomodades i en l'abastament de consell i gestió intel-lectual de les classes dirigents i àdhuc dels mateixos governants. Durant els darrers vint anys, l'Opus ha desenvolupat una àrea que no havia previst el fundador en els seus carismes fundacionals: les escoles per a pàrvuls i adolescents; el terreny prioritari de l'apostolat opusdeista en aquest moment no és només la Universitat, sinó la penetració en els sectors infantil i juvenil de l'educació.

El 1939 es va crear el Consell Superior d'Investigacions Científiques (CSIC), organisme cientific i universitari per renovar la gloriosa tradició científica de la Hispanitat i formar un professorat rector del "pensament hispànic". Fou una obra mimada pel règim com a instrument de propaganda del "nou ordre" creat pel "Movimiento Nacional". Els progenitors foren José Ibáñez Martín, el ministre, i José Maria Albareda Herrera, membre predilecte de l'Opus Dei; immediatament als seus inicis, el CSIC passava sota el control de l'Opus Dei i fou un important focus d'apostolat i expansió de l'Obra.

L'activitat de l'Opus entre el món intel·lectual, recolzant-se en la iniciativa del règim polític d'aleshores sobre els col-legis majors (decret d'organització de l'1 d'octubre del 1942), ha estat frentica des dels seus orígens. El mateix any 1942 hi havia a l'Estat espanyol 60 catedràtics de l'Obra i la infiltració més notable fou en aquests col-legis majors, on és segura una forta activitat amenys fins al 1952. Dades canten: el 1956 hi havia 50 residències en tot l'Estat, i el 1966, n'hi havia 139 ( 87 d'homes, 50 de dones i dues mixtes); una bona part estaven dirigides o regentades per l'Opus Dei.

El nombre dels membres de l'Opus Dei a Catalunya es fa difícil, per no dir impossible, de revelar; aquesta és una informació secreta de la qual, pel seu caràcter de no visibilitat, no queda ap constància. Només podem esmentar algunes aproximacions fetes per un responsable de l'Obra a casa nostra: "La importància de l'Opus dintre de l'Església és inqüestionable. A Catalunya hi ha unes cinc mil persones aproximadament i només amb seixanta capellans exclusivament dedicats a l'Opus Dei. Els numeraris som la minoria; la majoria són supernumeraris". La sensació és que l'Opus està floreixent en contrast amb la gran devallada de l'Església. Així ens ho confiava un supernumerari: "Dintre l'Església l'Opus Dei està proporcionant una gran allau de vocacions; de fet, és d'on més en surten. En contrast, quan mires els seminaris, veus que estan buits".

Els fundadors de l'Opus Dei a Barcelona són noms prou coneguts: Jiménez Vargas, Alfons Balcells Gorina i Laureano López Rodó. No tenien encara 21 anys i vivien en un piset; és per això

\footnotetext{
${ }^{2}$ Malgrat que arreu hi ha informacions bibliogràfiques del fundador i de l'expansió de l'Obra arreu del món, ens hem basat en les fonts següents: a/ Directes de l'Obra: Le Tourneau, D., El Opus Dei, Barcelona, Oikos-Tau, col. ¿Qué sé?, 36, 1986; El Opus Dei, prelatura personal, Madrid, Mundo Cristiano, Folletos M.V, 364-365, 1988; Cummings, D., Cistians ennig del món, Barcelona, Oficina d'Informació de la Prelatura a Barcelona, 1988; 26 preguntas a Monsefior Avaro del Portillo. Prelado del Opus Dei, Madrid, Mundo Cristiano, Folletos M.C., 409, 1985.
} 
que el van haver de posar en nom de Balcells, ex-rector de la Universitat de Salamanca, que ja tenia 24 anys. Els falangistes van sospitar d'un pis en el qual vivien en comunitat persones que no tenien el projecte d'ingressar al seminari. Se'ls va acusar d'homosexualitat i de portar una vida en comú i van anar a la presó, encara que en sortien poc després en veure l'error comès.

El padrí de l'Opus a Barcelona fou Fernando Valls Taberner, home religios, investigador científic, promotor cultural i d'acció política i financera. La delegació del CSIC de Barcelona sert el trampolí de l'apostolat opusdeista a la ciutat de Barcelona i, per tant, de la seva implantacióa Catalunya.

Aquí van començar a proliferar diverses obres corporatives de 1'Opus Dei: l'Escola Esportiva Brafa al barri de la Bordeta, el col-legi major Monterols (el 1949) per a nois, el col-legi major Dàrsena a Esplugues per a noies, el col-legi Xaloc per a nois i Pineda per a noies a l'Hospitalet de Llobregat, Viaró a Sant Cugat del Vallès, Bell-lloc del Pla a Girona, l'església de Santa Maria de Montalegre confiada a l'Opus Dei, l'Institut d'Estudis Superiors de l'Empres (IESE), etc.

\section{Doctrina}

L'Opus Dei, com a grup religiós, no té doctrina ${ }^{3}$. La seva és una defensa aferrissada del que proclama l'Església Catòlica portada sota el prisma d'una certa intransigència. Quan les circumstàncies ho demanen, s'invoca l'autoritat d'algun pare de l'Església i, quan no, es fa recurs a l'autoritat d'un pontífex actual'.

Sense doctrina específica, l'Opus Dei té el que se'n diu una espiritualitat. Una frase del seu fundador ho deixa ben clar: "el camí de la vocació religiosa em sembla beneït i necessari en l'Església...; perd̀ aquest camín no és el meu ni el dels membres de l'Opus Dei. Es pot dir que, en venir a l'Opus Dei, tots i cadascun dels seus membres ho han fet amb la condició explícita de no canviar d'estat". L'essencial, doncs, és ésser en el món; l'espiritualitat de l'Opus Dei és netament secular.

Per altra banda, és una espiritualitat que no polemitza amb les espiritualitats religioses; es només "un brot diferent de la perenne riquesa espiritual de l'Evangeli", en frase del seu fundador.

${ }^{3}$ Un supernumerari ens ha dit: "L'Opus no té un cos de teologia propi; de doctrina no en té perquè és la mateixa que la de l'Esglesia. L'Opus té unes eines per a la santificació i, sobretot, una ascesi".

Els capellans de l'Opus Dei tenen una llicenciatura universitària $i$, a més, s'han preparat amb un doctorat en sagrades escriptures, història eclesiàstica, dret cand̀nic, teologia o moral. Veritablement, només arriben al sacerdoci aquelih que tenen una vocació específica, només s'ordenen els que són cridats. Aquests capellans escriuen els seus llibres; però $\infty$ han fet un cos de doctrina". I el responsable de l'Oficina d'Informacio deia semblantment: "L'Opus no té una teologit pròpia; és més aviat una ascesi".

Una ex-numerària amb vint anys a l'Opus Dei matisava: "Quan tu tens una mica de vida interior i t'interem estudiar teologia (ells no tenen mestres de teologia), et trobes que tot camina, tots són mestres "que andan". No van mé enllà que la bàsica i molts capellans de l'Opus Dei tenen uns estudis de pa sucat amb oli; però ja val. No és l'essencial".

${ }^{4}$ La visió d'un supernumerari és aquesta: "L'Opus Dei és una institució dintre l'Església Catòlica darrera la qual existeix entre els membres i l'Obra el compromís de donar i garantir la formació religiosa; per tant, amb una finalita garantida al que diu l'Església, l’Opus Dei garanteix el sosteniment religiós. Dintre l'Església hi ha diðcesis, parroquies, congregacions personals; són formes jurídiques totes elles possibles i que es donen". I una supernumerària afegia: "De fet, dintre l'Església, l'Opus Dei és el que està proporcionant més vocacions i és d'on en surten més. Hi ha capellans diocesens que comparteixen la fidelitat entre el bisbe diocesà i l'Obra. El primer opusdeista que arriba a una diðcesi demana el permís al bisbe i és sempre el prelat diocesà que autoritza la presència de l'Opus". Una ex-numerària diu: "Que sigui reconegut per l'Església -i, sobretot, ara que estan tan ben vistos- els dóna moral. Qui porta les relacions públiques del Sant Pare ts un numerari que es diu Valls". El mateix opina un jove que hi va romandre un any: "Es una secta aprobada por la Iglesiay esto les da moral a ellos". 
Els elements més importants són dos. El primer és la santificació del treball com a mitjà especific de santedat i fent l'home co-creador i co-redemptor amb Déu (realitzat amb perfecció i fent un judici de valor sobre el mateix en funció de la doctrina social de l'Església), convertint-lo en una oració continuada a través de les virtuts teologals de la fe, l'esperança i la caritat i donant exemple com a camí de santificació dels altres.

El segon és la llibertat i la responsabilitat. L'amor a la llibertat ha d'estar connectat amb la mentalitat secular de l'Opus Dei que fa que cada membre actuï lliurement en el món segons li dicti la seva consciència i assumint les conseqüències dels seus actes. Es, per tant, una llibertat de consciència absolutament inseparable de la responsabilitat; sense llibertat no hi pot haver responsabilitat, ni sense responsabilitat, llibertat ${ }^{6}$.

Seria intolerable que un membre de l'Opus Dei pretengués comprometre l'Obra o l'Església quan expressa les seves idees legítimes i opinables; ningú pot presentar com a doctrina de l'Opus Dei el que només és reflexió personal. Aquesta llibertat i responsabilitat alhora es manifesta en el treball, en la política, en la investigació científica, en les ciències sagrades. D'aquí neix un pronunciat secretisme?

S Una ex-numerària amb llarga experiència a l'Opus diu: "Hi vaig entrar per un ideal religiós $\mathrm{i}$ ja havia acabat la carrera $i$ havia treballat. Tenia 26 anys i sabia el que feia. Em va costar entrar-hi perquè, per una banda, veia que era un ideal millor; però, per l'altra, m'agradava molt la famnia. No va ésser un enamorament, sinó una cosa reflexiva. Hi estava d'acord: buscava servir Déu a través de servir els demés i el que expliquen de l'Opus Dei ells mateixos és fantàstic -i encara un m'hi tornaria a apuntar-: santificar el treball ordinari i fer apostolat a través d'ésser una persona normal i corrent". I un mpernumerari: "No s'entén que s'hagi fet tant safareig amb l'Opus Dei i que sigui contemplat com una cosa estranya. De fet, el que es proposa és la santificació de la vida diària (al cap i a la fi és el que ba de fer tot cristià) i et dóna els instruments per a lograr-ho. Per a mi fou una descoberta el fet que una hora de la meva feina quotidiana podia ésser la millor orcío. Quan vaig entendre això, se'm va obrir un món. No és tan complicada, la cosa, i això hauria d'estar a l'abast de tothom". Un capellà diocesà de l'Obra afegeix: "Quan es parla a les constitucions de l'Opus Dei de la importància de tenir càrecs públics i, sobretot, de direcció com a mitjà d'apostolat, es refereix a la consideració de la necessària santificació de la vida diària i del treball, prenent-lo com un servei. El treball és considerat una oració tot i que sigui una càrrega; des d'aleshores, com més amunt, més servei a la societat $i$ als altres. El militant de l'HOAC es vol mantenir al lloc on està per fidelitat a la classe obrera i com esperit de servei a la seva pròia classe. Són perspectives diferents, són espiritualitats diverses".

Es interessant, pel que fa al treball com a mitjà de santificació, la publicació de Byrne, A., Santificación del trabajo andinario, Madrid, Oficina de Información de la Prelatura, 1984.

${ }^{6}$ Una ex-numerària diu: "Jo crec que és una secta en tant que a la gent l'acribillen perquè no tingui temps de pensar. l, a més, amb mentides perquè aquest amor per la llibertat, acaba essent una llibertat només per les coses que ells volen. Pet exemple, penso que és una immoralitat que una senyora hagi de donar unes joies perquè al Padre Escrivá li volen fer una capa plena de pedres precioses. I $m$ 'hi vaig oposar $\mathrm{i}$ a les senyores supernumeràries que jo portava ni els hi vaig voler proposar"

${ }^{7}$ Un capella diocesà de l'Opus Dei ho justifica: "El secretisme s'ha d'interpretar de la manera que no es tracta de publicar res que ens pugui fer semblants als religiosos; l'Opus Dei té un caràcter de secularitat que el diferencia radicalment de la vida religiosa en l'Església. Ja ho deia el Pare Escrivà: "quan una criatura està al ventre, encara és una gran desconeguda". L'Opus Dei encara busca els seus signes externs i és sempre una Obra que s'està fent; és millor, doncs, no marèixer amb banderes distintives de cap mena".

AJ Parlament italià, hi hagué el 1986 una interpel.lació parlamentària feta pel diputat Bassanini de l'esquerra independent sobre si l'Opus Dei era o no una societat secreta. El rebombori fou gran i la premsa se'n va fer un ampli ressò, i no solament a Itàlia. Heus ací un llistat de publicacions que van entrar a sac en aquesta polèmica amb un o altre sentit: Penorama, 16 de febrer i 16 de març, 1986; Avvenire, 6 de maŗ, 1986; La República, 8 de març, 17 i 20 de maig, 1986; Pollica Interna, 23 i 24 de maig, 1986; Rafat, A., "La batalla política por la ilegalidad del Opus Dei en Italia, a Tiempo, 31 de març, 1986; "El Opus interpelado" (editorial), a El Pais, 26 de maig, 1986; Arias, J., "Un fiscal italiano abre una investigación preliminar sobre el Opus Dei, a El Pafs, 26 de maig, 1986; Pistolesi, A., "La campaña contra el Opus Dei, al descubierto", a Epoca, 90, 1 de desembre, 1986.

Al terme de la campanya i de l'agitació informativa que la va rodejar, no es va poder provar que l'Opus Dei fos veritablement una societat secreta. De totes maneres, és important consultar l'obra de Walsh, M., El mundo secreto del Opus 
Sota aquestes premisses es donen dues mentalitats: una de religiosa fonamentada en th incomprensió del missatge fonamental de l'Opus Dei i procedent d'ambients religiosos i eclesials, i una altra de secular que respon a l'espiritualitat de l'Opus Dei $^{8}$.

\section{Organització general i forma de vida}

A l'Opus s'han de distingir dos grups clarament diferenciats, sempre tenint en compte les dues seccions fortament separades dels homes i de les dones. D'una banda, hi ha els numeraris, que són els qui integren de ple dret l'organització a través dels compromisos adquirits dels quals parlarem més endavant i que viuen en residències com si es tractés d'una família (així l'anomenen entre ells) ${ }^{9} \mathrm{i}$, també, els agregats (abans se'n deien oblats), que amb les mateixes característiques que els numeraris per raons familiars o situacionals purament circumstancials no viven comunitàriament; per l'altra, hi ha els supernumeraris, associats a l'Obra a través d'unes promeses que esmentarem $i$ que segueixen vivint la vida $i$ les responsabilitats de la seva pròpia famflia. Evidentment, la forma de vida és completament diferenciada ${ }^{10}$. Hi ha, encara, els anomenats col-laboradors, lligats a l'Opus d'una manera o altra, sense estar sotmesos a cap disciplina religiosa; àdhuc podrien tractar-se de no creients. Numeraris i agregats estan sotmesos a les mateixes obligacions i sostinguts pels mateixos compromisos".

La distinció és importantíssima pel fet que no viuen amb la mateixa intensitat la seva vida quotidiana dintre de l'Obra i no són pas pocs els casos que han comportat problemes greus amb les

Dei, Barcelona, Plaza \& Janés, 1989.

8 Aquesta estructuració de l'espiritualitat de l'Opus Dei es desprèn bàsicament de textos divulgats directament pet l'Obra. Als ja esmentats de Le Tourneau i Byrne i altres publicacions de propaganda i captació en què no hi consta un autor concret.

${ }^{9}$ Una ex-numerària amb llarga experiència dintre comenta: "Diuen que l'autèntica família és la de l'Obra i l'altrá h́ la de sang. A mi no em van portar problemes a casa perque ho vaig plantejar com una cosa ineludible; sóc molt decidida. Com que treballava molt, feia molt d'apostolat i tractava molta gent, no hi va haver pega; pero amb molta gent sí que $\mathrm{b}$ ha hagut problemes...perquè també hi ha minyones amb entrega total a dintre". "Jo vivia en residència, era numerària, 's fondo perdido". Hi ha les numeràries que fan vots privats de pobresa, castedat i obedìncia".

10 "Hi ha les supernumeràries, que són les que s'han casat i tenen la direcció espiritual que els hi dóna l'Obra. Els supernumeraris són matrimonis corrents que, a més de la direcció espiritual, guarden la línia que no tanquin les portes a la vida i com més fills millor" (ex-numerària amb llarga experiència). "Quan l'Opus Dei no era encara prelatura, abans del 1984, es feien vots privats de pobresa, castedat i obediència. Després de la prelatura ja no es fan aquests vots privats i nomén hi ha un compromís verbal d'acceptació del que l'Obra proposa; és una qüestió de fidelitat personal. A l'Opus Dei hi ba residències on habiten un quants numeraris (entre sis i vuit) que treballen en coses diverses i són els que s'encarreguen de la direcció espiritual; després hi ha tota la gran quantitat de casats que viuen la seva vida normal tot intentant trobar uas camins de santificació dintre la seva vida de cada dia" (supernumerari).

${ }^{11}$ Article 148 de les Constitucions: "S'exigeix un vot privat comunitari reconegut d'obediència. En virtut d'aquest vot, tots els membres de l'Institut, numeraris i oblats (avui agregats) professen una obediència plena i en tots els aspectes a President General i als propis superiors (...) un sa lliurement d'ells pels fins de l'Institut segons la norma de les Constitucions". Article 149: "Aquest els pot imposar, en virtut del vot d'obediència, preceptes vinculants en consciència referits a tot allio que pertanyi a les finalitats de l'Institut". Article 58: "Han de consultar sempre els superiors en totes les qüestions professionals, socials o altres encara que no constitueixin matèria directa del vot d'obediència, sense transferir al superior l'obligació de donar-hi una resposta". 
persones internes i les seves famílies ${ }^{12}$.

Aquesta singular denominació (numeraris/supernumeraris) arranca dels orígens universitaris de l'Opus Dei, puix que en context universitari hi ha catedratics $i$ un excedent de persones que solien dir supernumeraris. Adoptant aquestes expressions, es donava a entendre que els numeraris són els socis de ple dret, l'elit de l'Opus Dei, i els supernumeraris, els integrants de la massa. El numerari i l'agregat, en efecte, són les persones solteres, amb estudis superiors i relacions socials i personals excepcionals; el supernumerari és la persona casada i també la persona "que no val", sigui casada o no. Els cooperadors, per la seva banda, no són considerats socis de l'Opus Dei i ni ts necessari que siguin catolics; participen en algun acte i, sobretot, fan una contribució econdmica ${ }^{13}$.

Els supernumeraris, malgrat la distracció de les ocupacions ordinàries, estan obligats a les mateixes pràctiques que els numeraris i agregats. De totes maneres, en el cas de tots, i especialment els darrers, les seves obligacions diàries són complexes i prolífiques:

-en aixecar-se al matí, oferiment de totes les obres del dia a Déu.

-mitja hora per vestir-se i, fins un cert moment, es recomanava una dutxa d'aigua freda, costum que va caure en desús perquè es va deixar de recomanar.

-una hora d'oració al dia: mitja al matí i mitja a la tarda.

-missa i comunió diària amb deu minuts d'acció de gràcies.

-visita al Santíssim diària. Després de dinar, hi ha tres hores de "silenci menor" per poder pensar en el tema de l'oració que es farà després.

-recitació d'una pregària estereotipada imposada.

-rés de l'Angelus a les dotze del migdia.

-rés del rosari complet dels quinze misteris; encara que l'obligació afecta només cinc $i$, quan s'n fan quinze, cinc almenys $n$ 'han de resar pel carrer o en les activitats ordinàries habituals.

-han de fer un quart d'hora de lectura dels evangelis o d'un llibre d'espiritualitat.

-s'ha de mantenir constantment la presència de Déu en tots els moments del dia. Hi ha riquesa notable de tècniques per aconseguir-ho: l'expressió de jaculatòries, la disponibilitat d'una imatge o dels rosaris a la butxaca.

-s'ha de dur un cilici de punxes dues hores diàries i el dissabte a la nit o el diumenge al matí $s$ 'han d'aplicar disciplines. Aquestes mortificacions es continuen practicant, encara que s'han suavitzat per raons diverses.

-rés de pregàries al vespre i examen de consciència general. Aleshores comença el "silenci major", consistent a no parlar fins a l'endemà al matí per tal de preparar la comunió. Abans de ficar-se al llit han de persignar-se $i$ arrosar el llit amb aigua beneita i resar de genolls les tres

\footnotetext{
${ }^{12}$ Sobre els conflictes que hi ha hagut a l'Obra hi ha una abundant literatura. Com a mostra, n'indiquem les referències eguients: Moreno, M* A., El Opus Dei: anexo a una historia, Barcelona, Planeta, 1976 i La otra cara del Opus Dei, Barcelona, Planeta, 1978; Comas, J., "Jóvenes estudiantes de la RFA denuncian prácticas represoras en las residencias del Opus", a El Pais, 9 de juliol, 1983; Reyes, L., "Los padres contra las sectas", a Tiempo, febrer, 1984; Almm, "Yo lectora. La historia amarga de una numeraria del Opus", a Marie-Claire, desembre, 1987; Rodríguez, J.R., "Asturias: una exugregada denuncia al Opus Dei", a Interviu, 261, abril, 1988 i Rivas, M., "Al servicio del varón", a El Pais, 1 de maig, 1988.

${ }^{13}$ Les interpretacions de les distincions són diverses. Un capellà diocesà de l'Opus Dei ens deia: "El fet que hi hagi rituacions diferents dintre de l'Opus Dei està lligat a un altre fet, que és que hi ha disponibilitats diferents. El supernumerari, com que té les seves obligacions temporals, té també una disponibilitat limitada; els agregats i els numeraris, en canvi, tenen usa disponibilitat total". Una ex-numerària observava: "En una meditació un capellà de l'Opus donava l'exemple següent: bi ba gent a dintre que és or; però ells necessiten carn, és a dir, vocacions. Amb aquest or, compren carn. Quan l'or no convé, se l'expulsa i ja compraran carn; però l'or no interessa, ells volen carn i, si aquest or no es fa carn, s'expulsa. I aixठ es fa. A mi em va horripilar".
} 
avemaries de la puresa amb els braços en creu ${ }^{14}$.

Setmanalment, tot soci de l'Opus Dei està obligat a la confessió del perdó dels seus pecats amb el sacerdot i a la recerca del consell confidencial amb un altre director, que és sempre un seglar numerari de l'Obra. Es recomanen ambdues confessions i quasi s'exigeix que sempre siguin les mateixes persones ${ }^{15}$.

Quinzenalment hi ha el cercle, que és una reunió de mitja hora amb altres membres comentant unes lectures revelades o no i reflexionant col-lectivament a través d'un examen d'esperit sobre punts essencials de l'espiritualitat de l'Opus Dei $i$ interrogant-se si s'ha viscut o no: filiacioamor de Déu, pobresa, castedat, obediència, fraternitat, coses petites, apostolat, sinceritat,

14 L'experiència demostra l'ambivalència d'unes pràctiques tan complexes. Un jove ex-Opus diu: "El hecho de bacer tantas normas era una pesadez, era una presión psicológica grande. Nos decían de ponernos cilicios y aplicarnos disciplinas; es una malla que pincha por un lado y te lo atas con una cuerda, alambres que aprietan y se ponen en el muslo y decian que era para mortificarse la carne. Yo no me apretaba mucho aunque el cilicio sí lo llevaba durante una hora al día cuando iba a estudiar". I una ex-numerària: "Tot és com una praxi, perquè aquesta gent canvia la vida per un reglament; no és que tingui una profunda formació religiosa. A nosaltres, que veníem d'un ambient religiós més profund, no ens van ensenya res; el nostre mateix impuls d'entusiasme feia que vivíem del que teníem i que tornàvem a sentir. Però, quan arriben a un nivell, ja no passen: canvien la vida per un reglament, per un pla de vida. Es com la farmacopea: et passa això?, posa't un cataplasma. Que passa una temptació?, pren una dutxa freda o posa't uns cilicis o aplica't unes disciplines; cilicis dues hores diàries i disciplines els dissabtes. Es rigidíssim. A mi, al principi quan m'ho van dir, vaig pensar: em sembla que no podit treballar perquè estaré tot el dia amb aquestes coses, però és la capacitat humana que ho fa possible. Tres parts de rosari diàries, mitja hora d'oració al dematí $\mathrm{i}$ examen de consciència cada dia. Setmanalment confessió i direcció espiritual, confidència amb la directora, que era com una altra confessió: un embolic. Aix ł́s borrorós i tot aixð obligat. A més, bi havia el "círculo" en el que una de la casa, a una hora determinada, reunia a totes i es feia un comentari de l'Evangeli $i$ es parlava o del treball (com havia anat aixd o això altre) o les coses que venien del Padre (perquè tot es referia al Padre). $\mathrm{N}$ final jo deia que ens donaven el "pienso compuesto". Tot és el mateix, és horrorosa aquesta monotonia que no es renova, que no té el do de llengüles. Aquest do de llengües és el que permet fer amable una vegada més el que ja se sap. Alla en el "pienso compuesto" i "a lo bestia". Amb aquesta pluja de normes el que vaig notar és la desvirtuació de l'esperit; la vaig palpar $i$ aixo és una experiència terrible. Vaig notar que el que predicaven, no estava d'acord amb el que vivien. Cal escollir entre la doctrina $i$ la vida $i$ ho comences a dir. Ho dius una vegada $i$ t'ho accepten; però ho dius dugues $i . . . "$. En canvi, un supernumerari ho veu així: "La direcció espiritual és la que t'ajuda en la tasca quotidiana, la que t'orienta en el que et convé o no et convé llegir, la que en definitiva et dóna suport per santificar la vida de cada dia que, al cap i a la fi, és usa obligací fonamental en tot cristia". I un numerari: "La gent no s'ofega amb aquestes pràctiques perquè acaben essent una necessitat per a la persona; garanteixen la seva supervivència espiritual. Tot plegat, t'ajuda a assumir la relació amb Dtu i a viure plenament l'entrega personal a Déu". Finalment, un sacerdot diocesà de l'Opus afegeix: "La cotilla que suposa la quantitat de gests als quals t'has d'atenir es suporta amb facilitat per causa dels fruits que n'esperes. Hi ha coses que et fan patir; però ho suportes. Es molt més facil pels supernumeraris o pels associats que pels altres. Quan jo estava a l'Equador, com que la meva mare era gran, vaig tornar al pais sempre que vaig voler; en canvi els numeraris estaven alla. Hi ha gett a qui aquesta cotilla els va molt bé $\mathrm{i}$ d'altres pels qui això no és per a ells; hi ha de tox. A part de què també hi ha el rice que aquesta cotilla es torni una rutina perillosa".

15 Un jove ex-Opus ho manifesta aixi: "Me tenía que confesar con el cura un día a la semana. El director espiritual no es cura, es sólo el director del centro. Y decían que era conveniente bacerlo siempre con el mismo cura y ponían como ejemplo al médico. Yo esto lo veo lógico. Cuando me confesaba con otro cura que no era del Opus Dei, ipor qué tenía que decirlo?. Creo que es bueno ir siempre al mismo cura. Se trata de hacerlo con uno que te conozca. Yo no $z$ con qú intenciones iban; pero siempre lo vi claro con el ejemplo del médico. Yo a veces me masturbaba y, por vergũenza de decírselo a él, me iba a otro. Una vez se lo dije a un cura del Opus Dei y me dijo: ¿tu que eres del Opus te masturbas? Yo no tenía problemas con la masturbación, sino con ellos, pues para ir cada semana tenía remordimiento de conciencia. Alli uno no decide, lo decide el director. Puedes irte de putas, hacerlo todo; pero les engañas y entonces te tienes que salir porque estar all engañando no tiene sentido. Es una secta; pero no como CEIS. A las chicas las meten de criadas. Lo be comentado con jóvenes y me han dicho: pues esto no es tan malo. No sé". I un matrimoni supernumerari, discrepa: "L'originalitat de la forma del sosteniment de l'Opus Dei, que no es dóna enlloc, és que la formació espiritual es garanteix per medi d'una doble direcció. Hi ba la direcció espiritual duta a terme pel director d'una resiđència, numerari a qui vas a veure per tantes $i$ tantes coses que la vida quotidiana, i la que porta el capella de l'Obra amb qui et vas a confessar". (I la dona va afegir:) "Això seguráment que ho fan perquè tenen tanta feina els capellans de l'Opus Dei que no donarien l'abast d'atendre a tothom. Aleshores, si et vols entretenir una mica, tenim aquesta direccí espiritual seglar que allibera els capellans d'una feina que seria absorbent". 
perseverança, aprofitament del temps, unitat d'esperit, vida interior, pla de vida, mortificació, etc. Mensualment, es fa un retir un diumenge al mes; els numeraris tot el dia i els supernumeraris durant dues hores.

Anualment, el membre de l'Opus Dei està obligat a seguir una determinada formació; es tracta de cursets, trobades, retirs i exercicis espirituals. Tots fan uns exercicis espirituals una vegada l'any i mensualment fan un retir un diumenge del mes; els numeraris tot el dia i els supernumeraris durant dues hores. Finalment, a l'estiu es reserven vint-i-dos dies per fer un curset sobre les constitucions o el catecisme de l'Opus, que, malgrat que se'n coneix alguna versí, resta com una informació absolutament reservada als integrants de l'Opus. Aquestes constitucions s'han anat adaptant en el decurs dels anys; però la sàvia indiscreció ha fet que en poguéssim tenir una redacció completa de les que estaven vigents l'any $1950^{16}$.

Com a característiques pròpies del grup no hi ha més indicadors: ni el tipus de residència, ni l'alimentació (a part els dejunis preceptuats per l'Església), ni el vestit tenen res d'especific si exceptuem el fet, ja apuntat, de la radical separació entre homes i les dones ${ }^{17}$.

El que sí que mereix un capítol a part és el tema de les lectures que deriva en el seu contacte amb el món exterior. Dintre l'Opus Dei, el que s'ha de pensar, llegir o meditar es troba durament mediatitzat per la direcció espiritual. Es el director espiritual el que aconsella el que s'ha o no s'ha de llegir, i aquesta intervenció va molt més enllà que la simple recomanació. La informació exterior està fortament controlada i existeix una pràctica generalitzada, "la correcció fraterna", que poleix qualsevol interferència en aquest sentit ${ }^{18}$.

La correcció fraterna consisteix en l'acord del director espiritual i un determinat membre

\begin{abstract}
${ }^{16}$ Un jove ex-Opus explica la seva experiència: "En verano ibamos de vacaciones a un centro de ellos, pagando claro. Había piscina, capilla. Una vez al año hacíamos un retiro de tres días y en los retiros no se podía bablar. A cada uno le encomendaban algo por hacer: la bendición de la mesa, tocar la campanilla para la hora de comer, rezar el rosario y cosas afi. Ponfan una lista y a cada nombre le ponían un trabajo para hacer. Una hora de oración: media por la mañana y media por la tarde. En la meditación nos hablaba el cura durante media hora. El examen de conciencia por la noche y, tambíen por la noche, se comentaba una frase de la Biblia. El silencio decían que era para estar más en contacto con Dios. Siendo del Opus to lo tomas más en serio y alguno que no era cura también daba charlas. El retiro era para estar con Dios completamente". I una numerària ex-Opus afegeix: "Cada mes es feia un retir d'un diumenge sencer. D'exercicis se'n feien uaa vegada l'any i l'estiu una formació intensa durant vint-i-dos dies en una casa de formació apartada del treball, única i exclusivament estudiant el catecisme, estudiant això o allo. D'història de l'Església ben poca n'estudiàvem; em penso que mai. Es una cosa alarmant, enervant".

Aquestes rutines quotidianes, mensuals o anuals, estan profusament documentades arreu dels papers, tant des de dintre l'Obra com des de fora. Les fonts emprades ara són: Ynfante, Le Tourneau, Cummnigs, ja citats. A més, Magister, S., "Santa Facciatosta", a L'expresso, 8, 2 de març, 1986; "Il polipo de Dio", a L'expresso, 9, 9 de març, 1986; "Amore ocilicio", a $L$ 'expresso, 10, 16 de març, 1986; Quaranta, G., "Divisi da Opus", a $L$ 'expresso, 11, 23 de març, 1986; Peiró, X./Company, E., "Opus Dei: secta o església?", a El temps, 320, 12 d'agost, 1990; Miret, E., "Lo que conozco del Opus", IEl Pafs, 16 de gener, 1982; Fuentes, J., "Opus Dei. Los cruzados de Woijtyla, a Cambio 16, 737, 1986; Aroca, S., "Opus V. Asi se torturan", a Tiempo, 220, 30 de juliol, 1986 i Cantero, M., "Opus Dei y sectas", a El Correo Espafiol-El Pueblo Vasco, 18 de desembre, 1987.
\end{abstract}

${ }^{17}$ Aquesta separació es justifica facilment. "Es normal perquè en una residència on hi hagués homes i dones, sense voler-ho es farien facilment l'ullet, es cauria en la temptació $i$ aquestes coses s'han d'evitar. Ja l'organització piramidal de l'Opus, amb el seu cap suprem a Roma, té el consell superior d'homes $i$ un consell assessor de dones", ens ha dit un numerari. I un sacerdot diocesà de l'Opus Dei respon immediatament a la pregunta sobre la separació de sexes a l'Obra: "De fet, no els hi ha anat malament".

${ }^{18}$ Un jove opusdeista ens ho explica: "Siendo del Opus Dei no puedes ir a una fiesta, al cine, a una boda, al teatro. A una boda por ejemplo, si no es del Opus Dei, no puedes ir; si se hubiera casado mi hermano no st si me hubieran dejado, wendo del Opus Dei. Los libros los teníamos allí y el director espiritual me iba diciendo los libros que no se podian leer y, de los libros religiosos, sólo los que estuvieran reconocidos por la Iglesia Católica, si no nada. Hay una lista de libros reconocidos o prohibidos por la Iglesia que no se pueden leer. No me acuerdo si tenía que leer los que estaban en la lista o los que no estaban; pero sólo unos libros concretos. Allí uno no decide, lo decide el director". 
entorn de l'oportunitat d'avisar, corregir o amenaçar un altre membre que hagi pogut cometre qualsevol cosa que vagi contra "l'esperit de l'Opus Dei". L'abús d'aquesta intervenció caritatin és evident $\mathrm{i}$ és facil de comprendre que es deriva lleugerament en un vertader safareig. Evidentment, és per aquest camí que es controlen els actes més insignificants i una de les conductes que fan l'objecte d'un control ben específic és el de les lectures que trenquen les normatives direccionals de 1'Opus Dei $^{19}$.

Per altra banda, en la qüestió sanitària i, sobretot, quirúrgica, es dóna també un procts centrípet: els membre de l'Opus Dei són assistits pels metges de l'Obra i les intervencions quirúrgiques d'importància, realitzades als quiròfans de la Universitat de Navarra, l'obrn corporativa més notable des del punt de vista sanitari de l'Opus Dei ${ }^{20}$. I en el camp psiquiàtric, concretament, hi ha una especial prevenció davant de qualsevol ingerència de professionals que no pertanyin a l'Obra ${ }^{21}$.

Finalment, el sosteniment econòmic de l'Obra es realitza a través de diversos canals a part de les aportacions generoses dels col-laboradors. Els numeraris fan donació total dels seus bénsi, quan fa cinc anys que són a l'Opus Dei, àdhuc fan testament de tot el que tenen o poguessin tenir i el producte del seu treball redunda sempre en benefici de 1'Opus Dei. Però els numeraris no śn la majoria ${ }^{22}$.

Els supernumeraris, que són molt nombrosos, mensualment fan donació voluntària, decidida en la intimitat de la direcció espiritual, d'unes quantitats prèviament estipulades ${ }^{23}$. La deducció és facil: s'acumulen una gran quantitat de diners a través dels quals se sosté la infraestructura de l'Opus Dei i es poden realitzar les grans obres corporatives que hi ha escampades arreu del món ${ }^{\alpha}$.

19 Una ex-numerària ho expressa així: "Allà és com una piràmide on tot se sap; hi ha una xarxa d'espionatge a traví del medis de formació que t'asseguro que allà se sap tot. Perquè, a més, hi ha la correcció fraterna: si en una casa hi vivim tres i jo, per exemple, explico un acudit en un moment determinat, aleshores es comunica a la directora: em sembla que s'be passat, potser que se li digui alguna cosa. Arriba un moment que això es desvirtua $i$ et fan correccions fraternes contínuament. No es fa per mortificar, es fa per sistema".

${ }^{20}$ Fundada el 1952, erigida en Universitat per la Santa Seu el 1960 i reconeguda per l'Estat espanyol el 1962.

${ }^{21}$ Una jove ex-opusdeista ens ha dit: "A l'Opus em deien que els psiquiatres i els psicðlegs són com el diable. No accepten cap psicðleg de fora perquè, si et fan un autoanàlisi, no ha de sortir cap trauma de res (...) I de neurosis, n'hi ba moltes a dintre; de noies, moltíssimes. Totes amb injeccions, amb l'etiqueta d' "enferma", com diuen. Es com un refugi per a les persones dabils l'enfermetat; jo era una fiera en aquest sentit".

${ }^{22}$ Una ex-numerària amb llarga experiència diu: "Jo no cobrava res i tots renunciàvem als béns personals $\mathrm{i}$ havies de fer testament quan feies la fidelitat al cap de cinc anys -que jo l'havia fet- donant tots els teus béns a l'Opus Dei. No en a l'Obra mateixa, sinó que hi havia uns representants". I un jove ex-Opus precisa: "En el Opus lo que bay que bacet ingresarlo todo: todo lo que cobras has de darlo. Yo no lo hice porque no lo entendía y me quedaba una parte. De becho mi trabajo era en la Telefónica, totalmente fuera de la Obra, aunque entré en ella siendo ya del Opus Dei. Me decían qu todo el dinero lo tenía que entregar a ellos y yo debía pedir como limosna para lo que necesitaba. Los regalos, igual: si m bacían un regalo lo tenía que entregar a ellos. Creo que la cosa iba en si ponía mucho corazón en este regalo; si poní mucho corazón, se lo quedaba el director. Si no ponfas mucho corazón, te lo daban a ti".

${ }^{23}$ L'article 166 de les Constitucions ja preveu aquesta donació mensual dels supernumeraris.

24 "Els supernumeraris fan una aportació mensual i aixỏ per a l'Opus Dei és una cosa molt important. D'aquí véne una quantitat respectable de diners. Els que són de bona fe i tenen una bona posició (que generalment bo són perquè els de posició normaleta són els menys) fan una aportació com més generosa millor. Amb la quantitat de supernumeraris que b ha suposa unes quantitats molts importants. Per aixd s'han fet totes les obres a Roma i arreu", ens revelarà una ex-numeràri I afegeix: "Hi vaig estar-hi vint anys, dels quals cinc en residències, i després vaig estar en un negoci de l'Obra que feie veure que no ho era perquè tot ho tenen camuflat. Va acabar com el rosari de l'aurora, perquè hi posaven el capital e mateixos supernumeraris $i$ al front hi havia numeraris $i$ supernumeraris $i$, és clar, mai hi havia dividends perquè tot 
I aixd no és difícil endevinar-ho: la majoria d'entre ells exerceixen professions liberals i tenen càrrecs de responsabilitat en tota mena de societats lucratives $i$, per altra banda, entre els spernumeraris les persones amb precarietats econòmiques són comptabilitzables amb una certa facilitat. L'Opus Dei, per un cantó o l'altre, es mou entre les classes dirigents i més prepotents de ba societat ${ }^{25}$. Les necessitats econòmiques en garanteixen un raonable excedent ${ }^{26}$.

\section{Iniciació de nous membres}

Un tema recurrent $\mathrm{i}$ fonamental en l'espiritualitat de l'Opus Dei és el de la necessitat de fer postolat. Ja el 1979 Joan Pau II deia a alguns membres de l'Obra: "La vostra institució té com a finalitat la santificació de la vida ordinària romanent en el món, immersos en el món: però per trnsformar-lo i redimir-lo per amor a Crist".

Ja hem tingut ocasió de veure el singular ferment social que ha suposat l'Opus: primerament umb la penetració apostòlica en el món universitari i intel-lectual, i posteriorment a través dels wol'legis corporatius de l'Obra estesos per tot el món. Apostolat és sinònim de proselitisme dintre l'Opus Dei, i l'evolució tàctica experimentada obeeix només i únicament a un signe del temps ${ }^{2}$.

El proselitisme en els col-legis, les residències, les cases d'exercicis $i$ altres institucions directament lligades a l'educació, són les obres d'apostolat especifiques de l'Opus Dei. Una condició essencial per fer-se'n càrrec i assumir una institució com a pròpia és l'eficàcia. Dintre

brnava a invertir. Tenen uns mètodes econðmics a favor seu intel-ligentíssims i estudiadíssims. He treballat deu anys en una mpresa seva i no havia cotitzat mai a la seguretat social; quan en vaig sortir, $m$ 'he trobat que no tinc cap paper que pugui creditar davant de cap tribunal: jo no existia en aquella època. Se'n fien totalment de la fidelitat de la gent".

25 Ja en les Constitucions que coneixem ens deia a l'article 202: "Mitjà peculiar d'apostolat de la Institució el costitueixen els càrrecs públics, en especial els que impliquen l'exercici d'una direcci6". Per altra banda, només cal recordar l'epperit de l'Obra que inclou l'exercici de la professió com un mitjà de santificació, com una oració i com un servei. Des l'aleshores, com més amunt s'arribi, més gloria a Déu.

${ }^{26}$ Les suspicàcies $i$ atacs amb els corresponents contraatacs en aquest tema són inesgotables. Citem-ne algunes refertències: Ortega, A., "Un ex-miembro inglés del Opus Dei intenta recuperar el dinero que cedió a la obra cuando estaba ilegrado en ella", a El Pafs, 29 d'octubre, 1981; Gubern, R., "Dinero confesional", a El Períblico, 10 d'agost, 1983 ; Barnils, R., "L'Opus per fi", a El Món, 27 de juny, 1984; Aroca, S., "El 'padrino' del Opus y sus hombres de paja", a Tiempo, 217, 13 de juliol, 1986 i "El Opus. Los cerebros de todos sus negocios", a Tíempo, 218, 20 de juliol, 1986; Pérez, A., "Fraga en manos del Opus Dei", a Tiempo, 227, 21 de setembre, 1986 i Valls, F., "El Vaticano quiere modificar los wuerdos con España para que el Opus Dei goce de exenciones fiscales", a El Pais, 25 d'octubre, 1987.

${ }^{n}$ L'article 116 de les Constitucions diu: " $S$ 'ban de reclutar les persones que per la seva cultura, la seva caritat o altres walitats són considerats de gran pes per a les finalitats del servei que l'Obra intenta portar a la societat civil".

Tanmateix, un jove ex-Opus ens explica: "En el Opus Dei lo principal es el apostolado; pero yo nunca entendi que dobía decirle a un chaval de 15 años que se metiese en el Opus Dei. No me parece normal que busquen a la familia. Si es ma vocación ¿por qué ha de estar allí mi padre, mi madre, mi bermana? Si es una cosa de Dios, que vayan detrás de mi asdre no me parece normal". I una ex-numerària, per la seva banda: "L'Opus Dei va lograr una primera promocí d'intel-lectuals a través de les investigacions cientifiques (Josep M. Albareda era un sacerdot de l'Opus) i allà van fer una man captació. Aixd els hi ha baixat perquè la Universitat avui dia no està per aquestes coses, ha evolucionat. De fet, s'ba lesvirtuat. Això de santificar el treball ordinari sí es feia, perquè nosaltres feiem de minyones i portàvem pràcticament les wiministracions de les residències. De fet, això era la palanca perquè nosaltres després poguéssim fer el que feien a les rasidències. Vaig estar cinc anys fent el treball de les residències $\mathrm{i}$ fent apostolat entre les universitàries, i aixd a mi m'encantava. L'apostolat consistia en donar xarles a les estudiantes els vespres quan bavien acabat les classes. Pencàvem com a mules: ens llevàvem a les sis del matí fent la neteja de les habitacions amb les minyones (fer 130 llits sembla una netería; però et quedes sense ungles), la cuina, les compres, la roba $i$, a partir de les sis de la tarda, les que estàvem dissenyades per fer-ho, teniem les xarles amb les universitàries. Fou un exit: en venien a muntanyes $i$ amb un ambient cortial, bumà i cult. Va donar un bon resultat". 
l'Opus es valora extraordinàriament aquest concepte, encara que només sigui per una consideracío merament econòmica ${ }^{28}$.

L'Opus Dei s'autoabasteix amb els seus propis col-legis i aquests esdevenen un camí de reclutament $\mathrm{t}^{29}$. La captació individual entre els alumnes sol ésser insistent $\mathrm{i}$ amb constància, depenent sempre de la persona encarregada d'una determinada acció apostòlica ${ }^{30}$.

El passatge d'un sistema de reclutament intel-lectual i universitari a un sistema basat m l'escola d'estudis primaris o mitjans, ha suposat per a l'Opus una notable massificació, expressada sense equívocs per les persones que $n$ 'han viscut el canvi ${ }^{31}$.

A l'Opus no hi ha un ritual d'iniciació específica, encara que a les Constitucions de l'any 1950 es fa referència a la necessitat de consultar un cerimonial del qual ningú ens n'ha pogut donar raó en aquests moments. El que sí que fa és la redacció d'una carta que suposa un vincle de caràcter contractual, mutu i estable, entre la Prelatura i el fidel laic que, lliurement, desitja incorporar-s'hi. En el cas dels sacerdots, ens hem de referir al mateix procés dels laics perquè s'incardinen a la prelatura essent laics i és després que accedeixen al sacerdoci. L'absència total d'un vincle sagrat, fa que cadascú sigui essent un fidel laic normal i corrent de la diocesi a la qual pertany ${ }^{32}$.

${ }^{28}$ El numerari responsable de l'Oficina d'Informació de l'Opus Dei ens ha parlat així: "Vam acceptar de portar 4 direcció del centre sota la condició de donar-li un ple rendiment. Es tracta de donar als locals i a les instal-lacions un ple rendiment; és allo dels denaris de l'Evangeli. Quan hom veu aquests instituts tancats els tres mesos d'estiu, per les vacancet de Nadal $i$ les de Pasqua, totes les festes durant l'any, hom té dret a preguntar-se sobre l'aprofitament adequat de let instal-lacions, precisament perquè es tracta d'uns immobles que ban costat molts milions. Es perd un capital. L'Opus Dei el que intenta és fer rendir al màxim aquestes inversions. D'una banda, ens ocupem de la direcció acadèmica i, també, de crear un clima de rendibilitat a través de cursos diürns, nocturns, durant les vacances, etc.".

29 Una ex-numerària precisa: "Iniciació no n'hi ha; com que tenen els seus col-legis, fan el seu apostolat, fue proselitisme. Fan excursions, sortides i el factor humà està molt lograt, et trobes acollit, ho fan bé; parlen de les virtuss bumanes i a la gent jove això els capta. Entrega, oració, vida interior: coses que en si mateixes estan molt bé. Pel que ha la joventut: excursions, companyerisme, que estudiïn, que logrin els primers llocs, etc.".

${ }^{30}$ Així explica un alumne ex-Opus la seva experiència: "Tenía 16 años y tenía un amigo a quien los del Opus habiun estado detrás: iba a las charlas, le decían que se hiciese de la Obra aunque él dicía que no. Fue éste quien me babló de un médico amigo suyo que era del Opus Dei, lo conoç y este se me metió en mi vida: vino al entierro de mi abuela, $\mathrm{m}$ preguntaba por mis amigos... y fue a partir de aquí que empecé a conocer al Opus. La decisión fue mía, que quede claro. Acudí a charlar y a los círculos; quería conocer aquello. Al preguntarle al director espiritual qué era aquello, me dijo que ellos no bacían caridad, sino que sólo rezaban. Esto me cayó mal porque creía que era para hacer el bien; pero no me ecb́ atrás por orgullo: había decidido una cosa que tenía que seguir para adelante".

${ }^{31}$ Una numerària amb llarga experiència diu: "I això, durant un temps, francament no ho trobava tan malament. $\mathrm{N}$ contrari, molt bé. Però va venir la gran allau $\mathrm{i}$ aleshores es va desvirtuar totalment $\mathrm{i}$ allo ja era una plataforma de poder. Aquesta allau fou produïda per moltíssimes vocacions de tot aquest tinglado de supernumeraris i supernumeràries, tot aquek treball dels col-legis, de l'apostolat que nosaltres feiem amb les universitàries (Aquí a Espanya hi ba tres o quatre centrat de formació, em penso, i de numeràries "a fondo perdido", que vol dir amb entrega total com la meva, 60 o 70 residències). Aquesta massificació havia fet perdre aquell encant del principi. Es va produir que les més obedients eren les més tontea i les posaven en els consell locals de les cases, de tal manera que la directora, la subdirectora $i$ la secretària de cada casa tenia normalment un nivell més baix del de la resta $i$ aquestes havien de dir a les altres el que bavien de fer. Ho feien pet sistema, no pas per mortificar".

${ }^{32}$ Així ho han dit uns supernumeraris: "No hi ha cap ritus d'iniciació, només una carta demanant d'ésser admès. Si no hi ha proves de que aquesta persona no accepta l'esperit de l'Opus Dei, normalment se l'admet. No sabem qui ho decideix ni tampoc ens interessa massa". La muller afegeix: "Conec el cas d'una noia a la que es va orientar cap a uaa congregació religiosa perquè l'Opus no era per a ella. Es pot refusar l'admissió en tant que l'Opus no li convé i més aviat li convé una altra cosa". I una ex-numerària ens ha dit: "A l'Opus Dei tu hi arribes i hi ha sis mesos d'admissió i estàs en una casa de formació. Hi ha un catecisme que, en realitat, són les constitucions que ban anat canviant com els bi ba donat la gana $i$ et donen classes. Aquestes constitucions les estudies perquè és el "espíritu de la Obra". Ho has de saber de 
Es fa, doncs, una declaració formal, bilateral, de naturalesa contractual, feta en presència de dos testimonis, per la qual la Prelatura es compromet a garantir una contínua formació doctrinalreligiosa, espiritual, ascètica i apostòlica segons la direcció i l'esperit dels sacerdots de la Prelatura, il'interessat declara lliurement que està decidit a buscar la santedat $i$ a practicar l'apostolat segons l'esperit de l'Opus Dei, comprometent-se a restar sota la jurisdicció de la Prelatura $\mathrm{i}$ a assumir tots els deures de la condició de membre de l'Opus Dei, observant les normes de la Prelatura i les indicacions dels seus directors en matèria de règim, d'espiritualitat i d'apostolat.

A l'Opus Dei l'edat mínima exigida per a la incorporació és els divuit anys ${ }^{33}$. I no hi ha edat màxima, puix que hi ha persones que amb més de vuitanta anys han rebut la vocació a l'Obra.

No hi ha res en el que portem dit fins ara que ens permeti o ens autoritzi qualificar l'Opus Dei de grup sectari o ni tan sols de nou moviment religiós. Ni es troba segregat de l'Església, ni esta al marge dels valors imperants en la societat moderna; tot el contrari, cada dia està més vinculat a l'estructura de la religió dominant i majoritària i el seu "esperit" impulsa els seus membres a treballar amb les eines del món actual, tot inculcant la santificació del treball ordinari sota el carisma de l'eficàcia.

Per altra banda, d'innovació religiosa no en té massa, puix que dintre les estructures de l'Església, es mou amb criteris clarament regressius i assentats en una religió de prepotencia $i$ exclusivista segons el model viscut els anys de la seva fundació. L'Opus acaba essent un model o camí de santificació que, amb una mirada mínimament crítica i des de l'exterior, només fa que defensar l'immobilisme i l'acceptació absolutament indiscutida de l'autoritat constituĩda, refugiant-se en un ascetisme rigorós i disciplinat perfectament immers en la convicció dels seus membres que el que fan o pretenen fer és el que veritablement s'ha de fer si es vol aconseguir la perfecció de la santedat.

Amb tot, no són pas pocs els indicis que ens fan pensar que l'Opus Dei té uns mètodes que normalment apliquen les sectes més rigoroses ${ }^{34} \mathrm{i}$, per tant, plantegen seriosos dubtes entorn de la seva mateixa pràctica.

Un primer indici és la tècnica del control ambiental. Aquest, a l'Opus, es manifesta clarament en els numeraris que viuen en residències comunitàries, que poden ésser traslladats i obligats a un canvi de residència segons les conveniències apostòliques de la Prelatura ${ }^{35}$. Els agregats, per la seva banda, es troben en les mateixes condicions que els numeraris; però es pot arribar a pensar que es tindran en compte les seves peculiars circumstàncies de la vida que els permeten viure a part de les petites comunitats de numeraris.

Una altra via de control ambiental és l'obligació pràctica de realitzar actes comunitaris constantment, alguns de caràcter diari, altres setmanals, altres mensuals $i$ altres anuals. Per aquesta via s'aconsegueix que l'actitud receptiva dels membres, que ells anomenen eufemísticament "formacio", estigui garantida. De totes maneres, no s'hi endevinen condicionants pel que fa a les sortides de la residència, encara que és difícil que un membre de l'Obra mantingui relacions

memoria".

${ }^{33}$ Una ex-numerària ens ha dit: "Als 15 anys ja els deixaven escriure la carta d'admissió, que això és quasi un: perversió de menors. D'aqui han nascut als col-legis molts problemes, perqù̀ hi havia famflies que no hi estaven d'acord atres sí, perquè essent supernumeraris confiaven en aquest esperit i en aquest ideal".

${ }^{34}$ Els periodistes en diuen "destructives". El terme fou incorporat posteriorment per la psiquiatria i actualment s'aplic als grups que presenten les característiques més agudament significatives entorn del tema que estem tractant. Un altre elemet d'aquests grups dits destructius és que en un lloc o altre del món han tingut conflictes amb la justícia penal.

${ }^{35}$ Una ex-numerària ens ha dit. "Amb una papeleta et poden enviar lluny: "este año conviene que te vayas a Murcia' Aixo com tots els convents: et poden canviar de lloc, de treball $i$ et poden fer deixar el treball que més t'agradi". 
d'amics a fora $i$ les seves relacions socials no acabin essent dirigides i encaminades pel grup, \& tal manera que provoquin la ruptura de les relacions "naturals" de la persona.

Control ambiental, encara, quant als familiars amb qui es mantenen relacions normalitzader però pel que fa als numeraris, l'Opus Dei proclama que la famflia autèntica és la comunitat i l'altn és la família que neix de la sang. Àdhuc hem pogut veure la insinuació que la resta de la famplit participi de l'ideari secular de l'Opus Dei i que no són pas pocs els conflictes originats a partir de famílies que no veuen clara la pertinença a l'Opus d'un dels seus fills, alumne d'un colley qualsevol de l'Opus ${ }^{36}$.

La desvinculació del fidel de la seva propietat privada en el cas dels numeraris th tremendament radical. Ha quedat prou clara en la informació precedent, àdhuc preveient la futurn accessió a possibles béns: la pràctica del testament. Tot es legitima per l'esperit de pobresa pra com un compromis inalterable ${ }^{37}$.

Així mateix, es desvincula l'individu de la xarxa sanitària habitual i se l'indueix a resoldr els problemes quirúrgics i sanitaris de la seva salut només amb el personal de l'Opus Dei i amb un prevenció singular de tota mena d'intervenció psiquiàtrica. També es prohibeixen activitał públiques com hem pogut veure; aquest capítol de les prohibicions ens sembla inacabable mentr sigui en actes en els quals no participin membres del grup i, sovint, arriba fins a les més petiter $\operatorname{coses}^{38}$.

Hi ha control ambiental també pel que fa al règim de les lectures, com hem pogut veurh Tot ha d'ésser aconsellat i controlat pel director espiritual i aquí, encara, hi juguen let prohibicions ${ }^{39}$.

Amb relació a les tècniques de control biològic, només s'hi endevinen tècniques secundàries: els cilicis diaris, les disciplines setmanals, dutxes d'aigua freda quan hi th temptacions. En principi, rituals violents que poden produir lesions més o menys greus, malgrt que sembla que aquestes pràctiques s'han anat temperant. Com hem pogut veure, no es tracta de coses referides al segle XII, sinó que encara mantenen una certa vigència. I tot això es justifica per la necessària ascesi per atènyer una perfecció superior i una fidelitat més coherent.

Les tècniques de control psicològic es manifesten, primer de tot, pel context ambiental crear a partir d'una dinàmica de grup. No és tant un "bombardeig de l'amor" com una situació en la qual

${ }^{36}$ Una persona que fou numerària durant molts anys, ha dit: "Hi ha problemes quan hi ba gent que es vol fer de l'Opus Dei i se li ha dit que vigili, que la vocació és com una "lucecita" que qualsevol vent l'apaga i aleshores, si els pares sti oposen, que la vagin alimentant per a que aquesta vocació sigui forta. Creen un ambient nefast i els pares s'empipen; de loten maneres, això només ho fan les directores que no tenen criteri. Hi ha molta gent, sobretot gent jove, que ho fa. A una amip meva li va passar; el pare era ateu i l'Opus Dei va dir a la noia que era millor que no digués res a casa i va acabar que ha van desheretar els de casa".

${ }^{37}$ Una supernumerària ens ha dit: "I parlant dels compromisos, quin cristià pot defugir la pobresa, la vertadera pobra d'esperit? Quin cristià no ha de seguir els postulats de la castedat dintre l'estat de vida que hagi abraçat? Quin cristià n'h pot estar, del que l'Església proclama i el papa diu? Em fa patir contemplar la buidor dels cristians per manca de suponti ajut; sense un suport és impossible viure la fe".

${ }^{38}$ Un jove ex-opusdeista ens revela: "Mis padres estaban en una panadería repartiendo el pan y yo me fuí al retiro. Quizás tenía que haberlo decidido yo de no irme al retiro; el Opus Dei no me dijo nada. Y me fú́ antes de tiempo para ir a ayudar a mis padres y lo hice en auto-stop y eso estaba prohibido...Sobre relaciones sexuales, siendo del Opus Dei estab prohibido todo acto sexual".

${ }^{39}$ Una ex-numerària ens deia: "Es feia una revista, "La Table ronde", francesa i moltes altres revistes de l'Opus Dei. I deies: aquest article no $\mathrm{m}$ 'agrada. Ja et feien la correcció fraterna. Tot el que era de l'Obra t'havia d'agradar, tant si estam bé com no. Només ens deixaven llegir els llibres que estaven aconsellats per la direcció espiritual: ¡Ojo con las lectural: es un enemigo malo el pensar". 
hom acaba sentint-se molt bé i molt a gust; la dada empíricament es pot comprovar ${ }^{40}$. L'Opus Dei fa sentir-se bé i és evidentment gratificant per a aquells que tenen una aspiració de buscar la antedat en el món. En aquest sentit, ja hem pogut veure més amunt com es cuiden aquestes questions de les relacions humanes en els col-legis de l'Obra. No cal oblidar que aquest és un mecanisme de pressió que genera una dependència respecte al que diuen els superiors.

Hi ha una absoluta dependència del Padre, mecanisme de control psicologic més subtil i justificat per la gran veneració que el Padre Escrivá es mereixia i que es deu al prelat Alvaro de Portillo. Al Padre se'l venera, se'l llegeix, se l'escolta, se'l segueix. Tot el que diu no pot tenir ap mena de discussió: té la veritat de les coses i el més petit gest del Padre instaura doctrina i norma de conducta ${ }^{4}$.

La denigració de la personalitat de l'individu està lligada a la dependència de la direcció espiritual. Ja hem vist que a l'Opus Dei la direcció espiritual no és únicament un consell ni un suport, sinó que és una veritable autoritat que decideix pel subjecte i pren les decisions més ordinàries intervenint, àdhuc en les coses més petites $i$ insignificants. La persona no compta, deixa d'existir, és inapta per decidir per si mateixa.

A més, aquest mecanisme és doble: direcció espiritual i confessió setmanal. Es en el reducte de la consciència i sota la protecció jurídica i ètica del secret de la confessió o el secretisme moral de la direcció espiritual que la personalitat pot ésser més facilment reduĩda a la seva més mínima expressió. L'individu rep les normes, més enllà de les pràctiques prescrites perioddicament als membres, que li convenen (segons els criteri d'un altre) per ésser fidel a la santedat. I tot plegat es legitima per la conveniència d'aspirar ineludiblement a la santedat $\mathrm{i}$ a la fidelitat a l'esperit $\mathrm{i}$ l'espiritualitat de l'Opus Dei.

Es programen les activitats més quotidianes de la persona a través de la subtilitat d'aquest mecanisme de la direcció espiritual i de la confessió. Sempre ha d'ésser amb les mateixes persones i amb una periodicitat setmanal. Les transaccions que s'operen en el terreny de la consciència no

${ }^{40}$ Un jove ex-Opus confessa: "De hecho les había cogido cariño; me costaba dejarlo. Ellos dicen que son más que migos, son hermanos. Estuve a gusto allí aunque hubiera cosas que no entendía". I una ex-numerària diu: "Aixd sí: les coes eren impecables; hi ha virtuts humanes. Darrera d'aquí només queda l'afany de poder $i$ una molt bona gent que ho h tontament i molts que pateixen. Capellans neuròtics, la immensa majoria. Ells només són amics dels que els entenen $\mathrm{i}$ els altres son "los enemigos de Dios". Elis diuen: "no conviene, esta persona no conviene". I això és molt sectari...Quan parlis umb gent de dintre, només en trauràs lloances $i$ que hi ha gent que ha sortit rebotada perquè no n'era digna. A mi, per exemple, me'n van treure perquè era incomoda i no interessava perque feia escola. Jo no me'n arrepenteixo ni d'haver-hi etrat ni d'haver-ne sortit. Ha estat una experiència molt enriquidora: alla hi ha un mostruari de tota una gent que es un microcosmos, tant familiar, com política, com humana. El curiós que ens passa a les meves amigues $i$ a mi és que a fora podem viure allo que preteníem viure alla dintre; però ara amb llibertat i sense cap mena de reglament". I un supernumerari reflexiona: "A l'Opus hi he trobat certament un punt de referència que ha satisfet a bastament les meves expectatives. Hi be trobat l'apoi $i$ la fortalesa d'un sosteniment espiritual que no assolia de cap manera, puix que abans em costava molt de for oració...segurament una mica com tothom". I un capella diocesà precisa: "Jo busco en l'Opus el suport que no trobo per witres camins i res més; perd que no em demanin de renunciar al meu caracter diocesà. Seria més dur aixd que una proposta de canviar de diocesi, malgrat que un canvi d'aquesta mena $m$ 'ho hauria de pensar moltissim. L'Opus Dei $m$ 'ha donat a mi un ordre a la meva vida; de fet, sóc una persona profundament desordenada. La direcció espiritual realitzada per una personal molt més jove, per exemple, em va fer renovar les camises perquè jo visc sol $\mathrm{i}$ les coses les arranjo com puc $\mathrm{i}$ ¿ i, si les camises no queden tan ben plegades ni planxades, ja m'estava bé. L'Opus m'ha ajudat a ordenar, a tenir cura adhuc d'aquestes petites coses".

${ }^{41}$ Una ex-numerària ho explica així: "Al Padre te'l posaven a la sopa; era una cosa odiosa". I un sacerdot diocesa de IOpus Dei ho veu d'aquesta manera: "El fet que l'espiritualitat estigui tan centrada en el Padre Escriva -l'actual Nlvaro del Portillo també en rep la denominació de Padre- es justifica en tant que forma part de la unitat de l'Opus Dei. S'ha dit com vies tractés una mica d'un infantilisme ingenu; però crec que hi ha també una dimensió d'agraiment cap a l'Escrivá. Recordo pan va venir el fundador de la JOC a Astúries i els militants li van oferir de tot $\mathrm{i}$ el van festejar en gran manera. No es pot descartar aquesta dimensió de l'agraiment". 
són tals, sinó que es tracta més pròpiament d'imposicions.

El menjar, el vestir, els sentiments, les actituds, les conductes, les aspiracions, etc., són revisades en el terreny concret del secret de la confessió i la intimitat de la direcció espiritual. Sembla que aquí ens trobem clarament davant d'una tècnica de control psicològic tremendament dura. Serà el terreny abonat a les culpes $\mathrm{i}$ les pors generades entorn d'un reglament instituīt per l'Opus i entorn d'una normativa individualitzada i personalitzada en cadascun del seus membres.

I la coronació d'aquest control psicologic sembla que es troba en les represàlies organitzades i programades en el precís moment que una persona deixa pel motiu que sigui l'Opus Dei. Es desencadena, aleshores, una veritable persecució sota el pretext apostolic de salvar l'ànima d'aquella persona i de treballar obstinadament pel bé de la mateixa. Evidentment, els de dintre ho neguen obsessivament; però els testimonis són massa evidents per poder sostenir qualsevol mena d'engany o trampa en aquest sentit. 42

Aquesta por de revelar res a la sortida l'hem experimentat directament en el curs de la nostra investigació empírica, no solament per l'obsessió manifestada en el que s'ha dit, sinó també per fets puntuals que hem pogut viuree ${ }^{43}$. Les precaucions d'anonimat han estat una exigència constant $\mathrm{i}$ aclaparadorament persistent ${ }^{4}$.

Finalment, el control cognoscitiu es realitza a través de l'eliminació de tot sentit crític. No solament tenim els testimonis dels que han deixat de pertànyer a l'Opus Dei, sinó que hem pogut contemplar l'absència, segurament que subconscient, dels qui encara formen part de l'Obra. Els

${ }^{42}$ Un jove ex-Opus ens ha dit: "Tengo que reconocer que me persiguieron un poco. Salia del trabajo y mi amigo estabe en la puerta y me decía que no quería que yo hiciera algo de lo que después me hubiera de arrepentir y parece lógico el argumento". Una ex-numerària, per la seva banda, revela: "Quan vaig sortir, no hi va haver-hi problemes mentre no diguts res: oblida-te'n, tu ets morta, "la ley del silencio". Però conec el cas de la M*". Angustias Moreno, que després de sortir de l'Opus Dei i d'haver escrit un primer llibre sobre la seva experiència, fou acusada per capellans numeraris de l'Opus Dei davant d'unes altres noies que havien firmat una carta certificant que el que deia era veritat, que es tractava d'una lesbianu intentant desacreditar-la públicament. Jo vaig sortir-ne sense vocació i sense professió; després de vint anys, tota la meva preparació em venia d'abans, gràcies a Déu, perquè a casa meva hi havia molt bon ambient. Allà dintre tampoc em va tocar estar a la cuina contínuament com moltes, perquè vaig fer moltes labors $i$ vaig alternar amb molta gent. No em vaig enriquir culturalment; perd̀ humanament sí, i no pas per ells. Les millors amigues les he fet allà, encara que totes se n'han sortit. La llei general és que, si marxes o tens problemes sexuals, estàs "loca". El que els fa més ràbia és que a nosaltres no eau han pogut dir que bem sortit per un tio o que estiguem fent una vida normal i que practiquem; aixd els deixa sense recursow, perquè has d'haver fet coses anormals, perquè ells són els que et donaven la vida normal i et deien el que havies de fer. Si el que havies de fer a dintre ho fas a fora, no ho entenen perquè has estat fora de la barca". El numerari del Servei d'Informació de l'Opus Dei ho diu diferent: "Això de les represalies 6 s completament fals. Tot el que diu M" Angustia Moreno és fals i, a més, ha promogut una associació contra la beatificació del Padre. L'Opus és el que és i aquestes persones tenen un ressentiment; elles s'ho perden, en definitiva". Un capellà diocesà de l'Opus Dei reafirma: "No ho crec, que a aquestes persones que $n$ 'han sortit se'ls hagi tractat tan malament com diuen. Segurament que estan emportades per un cert ressentiment".

${ }^{43}$ Durant l'entrevista amb una ex-numerària, hi ha hagut una interferència telefonica d'una amiga que també havia estat a l'Opus Dei $i$, en dir-li la interlocutora que estàvem parlant d'aquest tema, des de l'altre cantó del fil telefonic aconsella d'anar molt en compte perquè les coses es diuen com es diven i pot haver-hi problemes i conseqüències. Acabada la conversa, ella diu: "Et demano, sobretot, que tinguis molt compte de l'anonimat".

${ }^{44}$ L'ex-numerària es vol curar en salut: "Tinguis cura que en el context de la conversa no surtin coses que donin llum i que em puguin delatar. Ara n'estic molt allunyada, de tot aixo, i només faltaria que, per tal d'ajudar a un amic d'una men amiga, $m$ 'organitzessin un conflicte. No és temor; però francament ja passo d'aixo. Es una cosa de la vida de la qual no me n'arrepenteixo $i$ ara no em vull complicar la vida; això és de sentit comú. Si aixd servís per canviar les coses, bé; pero com que això no té solució....Em vindrien aqứ $\mathrm{i}$ em farien la vida impossible, perquè són capaq̧os de tot". 
testimonis són massa clars per deixar aquest important tema en silencis.

En les nostres converses amb persones de l'Opus Dei, hom té la impressió que de coses de dintre en saben ben poc, àdhuc potser ni els interessa. L'Opus Dei interessa en tant que garanteix solidament la seva espiritualitat i, sobretot, l'ascesi i això no es cansen de repetir-ho. A partir d'aquí, s'ignoren moltes coses de la institució $i$ expressament se'ns ha manifestat que en passen molt, de saber-ne més ${ }^{46}$.

Es evident que es manipula la realitat sense manipular expressament el llenguatge. D'una banda, hi ha un control de la informació a través de la direcció espiritual i, d'altra banda, aquesta possible manipulació no és tant el fruit d'unes persones més o menys obcecades, sinó que és clarament el fruit d'un sistema".

El resultat d'aquest sistema queda perfectament expressat pel resultat que se'n segueix. A causa de la forta repressió i control patit pels diversos membres de l'Opus Dei, a l'hora que arriba el moment crític d'abandonar els compromisos adquirits amb la institució, les persones confessen trobar-se en una situació qualificada per ells mateixos d'estranya. Es el mateix que experimenta una persona qualsevol després d'haver patit un cert temps un tancament en un internat. Hi ha dificultat d'autodefinir-se i surten a la llum problemes que hom era incapaç de preveures.

${ }^{45}$ Una ex-numerària diu: "Arribava un moment que les persones que tenien una mica més de sentit crític...Això del rentit crític estava fatal; anul-len deliberadament el sentit crític. Aquest només serveix per alabar les coses de l'Opus i tot el que va en contra de l'Opus Dei és de "los enemigos de Dios". Aixd crea la mentalitat que només ells tenen la veritat: hi ba un sentit de clan organitzat amb una massa andnima de gent de bona fe que son com la guerra santa: "matemos al enemigo". Un dia un capella, quan havia acabat de fer una explicació en un oratori femení de 60 persones, es va trobar que una noia el va anar a trobar com si fos el director amb qui cada setmana havíem d'enraonar, com si fos la confessio, i van fer un examen particular. El capellà li va dir: "Benita, no pienses". Ho vaig trobar aterrador: tu, d'examen particular, has de dir "Benita no pienses". L'important és que no pensis perquè ja a Camino hi ha una sèrie de jaculatòries que són la farmacopea per a totes les situacions". Una supernumerària s'expressa així entorn del tema: "Només es tracta d'ésser fidel en allo que és manat. N'hi ha que es pregunten per què ban canviat tant les coses. Crec que no s'ha de discutir i només nteair-se a les coses que es van prescrivint dintre l'Església".

${ }^{46}$ Uns supernumeraris ens han dit: "Qui és qui dictamina i decideix sobre l'admissió d'una determinada persona una vegada feta la sol-licitud d'admissió? No ho sabem, i nosaltres en passem una mica, d'aixd. Hi ha un Consell General a Roma, bi ha consells provincials i consells locals. No ens interessa saber-bo".

${ }^{47}$ Una ex-numerària reflexionava: "Al principi, em feia l'efecte que no era la institució, sinó que eren les persones les causants de la situació. A través del que veia amb el règim d'en Franco i comparant-ho, vaig arribar a veure que no eren les persones sinó el sistema. I aquí ja vaig fer el salt mortal. Podia ésser per causa d'una persona tonta; però quan veus que tael sistema $i$ quan veus que les persones son manejables pel sistema, $E s$ aleshores que dius: $m$ 'he equivocat $i$ ara ho pensaré clar. Vaig acabar dient: a mi $m$ 'han enganyat. El que jo veia i que predicava als demés, 6 s el que s'han trobat a dintre, $i$ em sentia culpable d'aix perquè no ho deia convençuda".

${ }^{48}$ Un jove ex-Opus ens ho explica: "Después de salir todo empezó con la obsesión de una chica. Estaba pensando en la chica y en el trabajo no rendía nada. Duró poco tiempo: cuando vef́a a una chica, me entraba un poco de emoción; es como cuando hace tiempo que no ves a una persona. $Y$ cuando después fú a ver a los del Opus, me di cuenta que de amigos so tuve en el Opus Dei; alli me dedicaba a rezar y no a hacer amigos entre ellos. Había personas que se lo pasaban bien Ulli; ésta era la impresión. Yo no, me lo tomaba muy en serio, aunque estuviera engañado, claro. Si la idea de secta es que i una persona de 15 años la pueden sugestionar, creo que a mi me han sugestionado. Tampoco lo tengo claro, porque esto de secta es muy fuerte. Lo de la sugestión, sí: por medio de bechos o actividades meterte algo que a ellos les interesa. Cuando estás sugestionado, no puedes decidir tu, y yo no tenía decisión". Una ex-numerària, per la seva banda: "El fenomen de la gent de l'Opus Dei, quan l'expliques després de setze anys d'ésser-ne fora, et sembla que és impossible. Jo que em peosava que era tan llesta ¿com he pogut Esser tan idiota de veure-bo després de vint anys? La crítica va néixer en mi de a realitat de fora comparada amb el que vivia allà dintre. Jo estava molt a fora perque hi tenia un treball $i$ la familia $i$ zermans i llegia les Questions de vida cristiana de Montserrat, que fou un regal d'una senyora "progre" que em va fer l'obsequi de la subscripció $i$ jo ho llegia perquè aqú no hi va arribar l'espia $i$ allà es parlava dels fdols, de la llibertat $i$ faltres coses. Vaig veure que hi havia molta més doctrina que no pas a dintre. Precisament, jo ja tenia una bona base, un bon bagatge des de casa i, des que tenia ús de rá, havia viscut de cuidar les coses petites. Me'n vaig adonar que ells cuiden 
Els debats sobre l'Opus Dei a la televisió pública sempre han incidit constantment sobre aquest tema $\mathrm{i}$ es pot consultar una gran $\mathrm{i}$ abundant literatura, a vegades afirmant aquesta manipulació i d'altres negant-la".

\section{Relacions amb la resta d'institucions}

L'estreta vinculació de l'Opus Dei amb l'Església catolica fa que la relació externa amb altres institucions sigui perfectament normalitzada. Hom té la impressió que l'Opus Dei, per raons de penetració apostolica i proselitisme, empra les institucions que li convenen com a plataforma de presència i d'eficàcia, i això ha estat així des del començament. No és una casualitat que el món universitari i professional sigui el lloc predilecte, puix que els seus numeraris han d'estar to possessio d'un títol universitari i, per tant, estan distribuïts, manifestament en molts àmbits de poder i de decisió. Es la mateixa fidelitat a l'esperit de l'Obra que requereix que les coses siguin així.

Més enllà del món acadèmic i de la docència, l'Opus és present en el món del funcionariat, de la política, de la banca, de la construcció, de l'automóbil, de l'agricultura, de la tecnologia de punta, de la mineria, de la siderúrgia, dels serveis, dels transports, de la indústria en general, del turisme, etc. Hi trobarem catedràtics, periodistes, advocats, economistes, arquitectes, artistes, actuaris, militars, sacerdots, bisbes, notaris, etc.

Estem simplificant excessivament les diverses informacions que tenim d'un ampli ventall de presència opusdeista. De totes maneres, ja hem vist la tendència de l'esperit de l'Opus en tant que aquestes activitats i aquests càrrecs no són com a representants de 1'Opus Dei, sinó que en virtut de la llibertat i la responsabilitat proclamada, ho són per la seva característica apostòlica i per la seva missió específica d'apostolat personal; no representen l'Obra, sinó que es representen a si mateixos. Aquesta és una característica bàsica i fonamental de l'esperit de l'Opus Dei.

\section{Alternatives existencials del grup}

El perfil del membre de l'Opus no és diferent que la fisonomia moral d'un cristià qualsevol; al cap i a la fi, només extrema la seva fidelitat a la fe seguint el camí prescrit, aconsellat i manat a les constitucions de l'Opus Dei que responen a un determinat esperit. Un esperit que és més una ascesi que una doctrina; però al cap i a la fi una ascesi que es tradueix en pràctiques múltiples que només tenen la intencionalitat de guiar i encaminar el soci vers una perfecció cristiana. Aquesta $t$ en síntesi l'oferta que fa l'Opus i hom diria que és susceptible d'entrar-hi aquell a qui els camins

les petites; però de les grans no en cuiden ni una. De fet, s'ha d'ésser molt fort físicament i psíquicament per aguantar aquent acribillament constant. I enfrentar-se, perquè arriba un moment que estas com...t'entra la por. I fou com una clarividexcil comunicada; en parlàverm entre nosaltres sense dir-ho a la direccio -i aixo era una cosa molt mal feta; en tot cas s'havi d'haver comunicat al director-. Hi hagué una comunicació humana entre persones que vam ésser amigues, va agafar envolada i vam sortir tot un grup".

49 Només per la via de l'exemple, després d'un programa televisiu del 1988, vegeu: Sales, F., "Un portavoz de ha prelatura ha desmentido la práctica de las terapias", a El Pais, 11 de juliol, 1988 i La Vanguardia, 27 de juliol; Urbano, P., "TVE ataca al Opus Dei", a Castellón Diario, 31 de juliol, 1988 i a Avui, 28 de juliol. El 1992 amb motiu de ha beatificació de J.M" Escrivá i posar sobre la taula altra vegada el tema de l'Opus Dei, hi va haver una forta polemica que es va traduir en molta literatura i una abundant proliferació d'actes públics, adhuc pels mitjans de comunicació social. 
de seguiment de la vida cristiana necessiten d'un ajut, un suport $i$ una coherència ${ }^{50}$. Es innegable que la cotilla que l'Opus Dei imposa, per a moltes persones, pot ésser necessària.

Un component pràctic de l'Opus Dei és el rigor amb què es prescriu i es practica la separació entre els sexes. Deixant a part les residències d'homes i de dones, sempre en règim de separació total, a nivell de praxi s'encamina les persones a reprimir la més petita promiscuitat i a controlar radicalment els propis sentiments i les fantasies més diverses; la fidelitat al compromís de castedat arriba a extrems que semblen exagerats ${ }^{51}$.

La moral sexual dintre l'Opus és estricta, rigorosa i no admet contemporitzacions. S'ha de resoldre en el perdó de la confessió i, quan hi ha problemes, és motiu suficient per considerar una determinada persona indigna. Tanta repressió pot ésser motiu de neurosis, com algú ha deixat a entendre. Recorda les reflexions fetes per Lewis Coser a Instituciones Voraces ${ }^{52}$.

\section{Conclusions}

Déu ens guardi d'interpretar que l'Opus Dei pugui ésser etiquetat de secta! Aital afirmació, ni encaixa amb la teoria sociologica de la religió quan ha tractat del tema de les sectes, ni ha d'ésser tan sols usada capriciosament. Ni en broma! Seria un vertader abús. I nosaltres volem moure'ns en el context de la ciència 0 , almenys, pretenem no partir de cap afirmació que ens pugui venir de la sociologia espontània.

De totes maneres, trobem dues elaboracions conceptuals que encaixarien en la interpretació del que hem pogut observar a l'Opus Dei; una ens la dóna la sociologia i s'expressa amb el terme

${ }^{50}$ Un supernumerari ens ha dit: "Tenia un amic capella de l'Opus Dei als Estats Units, i quan jo treballava $i$ anava completament absorbit per la feina i experimentava la buidor que és dedicar-se només i únicament a la feina, em va enviar uas felicitació de Nadal. Feia temps que no l'havia vist. Li vaig contestar una carta dient-li si hi bavia alguna cosa en I'Església que pogués ajudar-me espiritualment en la meva tasca diària $i$ és aleshores que, sota el seu consell, em vaig escaminar a l'Opus Dei. Posteriorment, la meva dona també seguiria el mateix camí uns dos anys més tard. Suposo que hi bu matrimonis en què un ho és i l'altre no; però no sé com s'ho deuen arreglar. Passa segurament com en tantes coses del watrimoni quan ambdós no van alhora*.

${ }^{51}$ Aixf ho explica una supernumerària: "La direccí́ espiritual es porta per separat entre el meu marit i jo; hi ha la idea que la forma d'entendre les coses de l'home i de la dona és diferent i que, per tant, la direcció espiritual també ha d'ésser diferent". I el marit afegeix: "Nosaltres hem tingut cinc nois i vuit noies; ara ja $n$ 'hi ha alguns de casats i en tenim una que ja bs numerària i tres més que s'estan preparant per ésser-ho. El compromís de castedat és precisament fer les coses tal com ba d'esser $i$ és per aixd que hem tingut tretze fills. La meva dona $i$ jo ara estem fent les nostres meditacions sobre textos difereats perque la direcció espiritual no és portada per la mateixa persona".

${ }^{\$ 2}$ L'ex-pumerària ho insinua: "La moral sexual és rígida; perd no sé com dir-tho, allà hi ha de tot. Si tu ets una persona normal, no és rígid perquè t'atens a allo que has promès. Ara bé, hi ha molts casos de neuròtics; però això passa mb tot: convents i seminaris. Per a les persones sanes que tinguin interessos intel-lectuals $i$ un treball que més o menys els oepli, no n'hi ha cap, de problema. Són ells el problema, perquè fan unes separacions de sexes terribles: el director per un cantó i la directora per un altre, tot a traves d'un "telefonillo" interior. Només es diu el mínim: "pax", "in tecum", "tantos para comer", "tantos para cenar", falta aixo, falta allo. Els capellans viuen amb els nois i a través de la direcció upiritual incideixen en les noies. En realitat, la secció femenina també la governen els bomes. Que diguin el que vulguin; mor l'Escrivá ja deia: "la virgen, la madre y la buena cocinera". Es al servei del varó $i$ "el descanso del guerrero sin krecho a cama", així de clar. De totes maneres, aixd̀ passa també en moits matrimonis. La moral sexual no assumida provoca neurosi $i$ molta gent rara, efectivament. Una persona que tingui un mínim de temperament independent $i$ autonom, hit enfronta. En canvi, aquesta gent està mediatitzada. Es allo que diuen les casades: "como dice mi marido...". Sentint-ho Ila platja vaig acabar pensant: "mira, en todas partes cuecen habas". Les amistats particulars dintre l'Opus Dei són nefastes; pero, des de quan totes les amistats del món són col-lectives i no particulars? Es la individualitat que fa l'amistat. En aquest notit, mai $m$ 'hagués imaginat passar-ho tan malament estant tan bé". 
d'"alternació"s3, i l'altra prové de la psicologia i és la "teoria de la dissonància cognitiva"s. Creiem poder afirmar que ambdós adquirits conceptuals són perfectament apropiats al cas de l'Opus Dei.

Què és l'alternació? Es el procés a través del qual una persona viu un procés social que transforma totalment la seva realitat subjectiva; implica un procés de ressocialització molt semblant al de la socialització primària, la qual cosa vol dir que ha de reproduir aquella forta identificacio afectiva amb els agents socialitzadors, característica singular i específica de la infancia. $A$ diferència, però, de la socialització primària, qui està sotmès a una alternació no parteix de zero, sinó que es troba amb el problema que ha de desmuntar i desintegrar la prèvia estructura de ha realitat subjectiva.

El procediment s'emmarca en unes determinades condicions socials, la més important de les quals és l'existència d'una estructura de plausibilitat eficaç; és a dir, d'una estructura o d'alğ que faci evident $i$ jugui el paper de legitimador fent subjectivament significativa la totalitat de b vida de l'individu. La vida de l'individu adquireix un significat en el context de la vida institucional on es troba. La legitimació justifica l'ordre institucional a base de donar valor pràctic a tots ets imperatius que vénen donats per les normes.

Es dóna una identificació afectiva amb tots els que formen part del grup de referència i que integren aquella estructura de plausibilitat que actuaran de guies de la nova realitat.

Socialment, es dóna una interacció significativa entorn del grup, i especialment amb el personal encarregat de la tasca de ressocialització.

Com hem pogut veure, a l'Opus Dei es dóna un procés d'integració i de pràctiques que suposen una vertadera ressocialització de la persona; aquest concepte d'alternació hi és perfectament aplicable. A més, tot el grup que participa de les mateixes conviccions juga un paper ressocialitzant, especialment el Padre, la Societat Sacerdotal de la Santa Creu, els directors espirituals (que excepcionalment són sacerdots) i els confessors; els dos primers de caràcter públic i garantint les veritables essències de l'"esperit de l'Opus Dei", i els dos darrers actuant secretament i confidencialment a l'interior de la consciència.

No creiem que se'ns pugui acusar de partidistes si interpretem aquests fets $i$ aquestes pràctiques des de la perspectiva de l'alternació. Per altra banda, és l'única manera de comprendre com tantes i tantes persones intel-lectualment molt preparades es comporten dintre l'Opus Dei sense el més petit esperit crític; en el context d'una mínima racionalitat, això no troba cap més explicació. Quan hom contempla la infinitat de petites pràctiques a les quals són sotmesos els fidels, hi ha el dret a preguntar-se si tot es pot justificar només i únicament a partir de la recerca de la santedat.

Pensem que en aquest aspecte hi ha pràctiques veritablement sectàries dintre l'Opus Dei i hi ha l'esforç d'assegurar aquella ressocialització o alternació prohibint lectures, condicionant les relacions socials i provocant persecucions sistemàtiques a la sortida de la institució.

La "dissonància cognitiva", per la seva banda, és la validació social de proposicions difícils de validar. Efectivament, el poder suposa, entre altres coses, la capacitat d'imposar els processos de socialització; és a dir, la facultat o poder de crear la realitat.

Hi ha simbolitzacions molt abstractes (allunyades de l'experiència concreta de la vida quotidiana) que tenen tendència a ésser validades socialment i no pas per pròpia experiència. Es tracta, ni més ni menys, de les visions de les coses que resulten convincents perquè funcionen des del punt de vista pragmàtic; es converteixen en coneixements evidents i donats per descomptats a

\footnotetext{
${ }^{53}$ Berger, P./Luckmann, Th., La construccí́ social de la realitat, Barcelona, Herder, 1988. (L'original anglès és de 1966).

S4 Festinger, L., A theory of cognitive dissonance, Row, Peterson \& Co., Evanston, III, 1957. 
la societat en qüestió, sense necessitat de més proves.

En el nostre estudi sobre les sectes ${ }^{55}$ vam descobrir que una constant de les institucions que empren mètodes sectaris és la provocació d'aquesta dissonància cognitiva; és a dir, et poden fer creure que un camell passa pel forat d'una agulla sense la més mínima comprovació de fiabilitat. Els grups esotèrics són prou característics d'aquesta tendència; però de cap manera en tenen el patrimoni exclusiu.

Pel que hem pogut observar, aquesta dissonància cognitiva també es dóna a l'Opus Dei. Només cal referenciar i recordar la profusió d'idees ascètiques i d'afirmacions categòriques lliurades de manera dogmàtica, l'absolutisme de la credibilitat proposada com a indiscutible entorn de l'absoluta bondat superior de l'Opus Dei per damunt i més enllà dels ordes religiosos i adhuc de la mateixa Església, la superioritat exclusivista de tot el que proclama, escriu i diu l'Opus Dei, etc.

Per a l'adepte i soci numerari o supernumerari de l'Opus Dei, ni cal verificar empíricament la veritat del que se li està preceptuant $\mathrm{i}$ proclamant des de la tribuna interior, perquè amb tota certesa es tracta de proposicions veritables i de missatges carregats de fiabilitat en si mateixos. Tot atac a les persones o a la institució de l'Opus Dei és obra del maligne, que es deixa emportar per la ignorància o per una positiva mala fe.

Potser el màxim que podem afirmar és que tant el procés de l'alternació com l'efecte de la dissonància cognitiva sigui un tret comú de molts grups sectaris que els periodistes qualifiquen de "destructius".

L'Opus Dei, malgrat els sovintejats reconeixements i benediccions del papa actual, té veritablement mètodes sectaris. D'aquí que sigui una institució tan polèmica dintre la mateixa Església catòlica.

55 El títol és Totalisme $i$ voracitat. Fou encarregat per l'Associació Pro-Joventut a l'Institut Catòlic d'Estudis Socials de Barcelona i, segons sembla, serà publicat per la Generalitat de Catalunya. 